\title{
Input to orepass design - a numerical modelling study
}

\author{
J Sjöberg Itasca Consultants $A B$, Sweden
}

A Bolin Itasca Consultants $A B$, Sweden

A Sánchez Juncal University of Alberta, Canada

T Wettainen $L K A B$, Sweden

D Mas Ivars Itasca Consultants $A B$, Sweden

F Perman Itasca Consultants $A B$, Sweden

\begin{abstract}
Orepasses are an integral part of the mining infrastructure in sublevel caving. As part of the investigations for potential continued deeper mining in the LKAB Malmberget mine, a study on orepass design has been completed. The initial portion of the work involved numerical modelling and rock mass strength calibration of observed orepass fallouts, and spalling failure in a ventilation shaft. The calibrated numerical model was subsequently used to study different orientations and locations of orepasses for a potential haulage level at depth.

The initial calibration work showed that a brittle material model - more precisely a cohesion-weakening friction-strengthening (CWFS) model - was required to replicate both initiation and extension of stress-induced failure. A set of rock mass strength parameters was derived and further used in forward model prediction for planned orepasses. A large number of alternative scenarios were explored, in which orepass orientation and location, as well as material parameters, were varied. Orepass wear was simulated by creating a groove at the bottom of the orepass. Progressive spalling (stress-induced) failure was modelled in selected cases, by removing rock that was encapsulated by a contiguous shear band and the orepass wall in an iterative manner. The results are used in the design process for selecting suitable orepass locations.
\end{abstract}

\section{Introduction}

The LKAB mining company is currently carrying out investigations for a potential continued mining at depth in the Malmberget mine. This iron ore mine is located in northern Sweden, approximately $70 \mathrm{~km}$ north of the Arctic Circle, and 1,200 km north of Stockholm. The mine comprises several orebodies of varying size, shape, and orientation, over an area of $8 \mathrm{~km}^{2}$. Mining is conducted using sublevel caving, to deliver an annual production of 15 million metric tons of crude ore. Mining is currently ongoing between the 569 and $1052 \mathrm{~m}$ Levels, corresponding to approximately $400-900 \mathrm{~m}$ below the ground surface. The current main haulage level is denoted M1250 and is located at the $1250 \mathrm{~m}$ Level. A potential new main haulage level would tentatively be located at the $1500 \mathrm{~m}$ Level.

A number of rock mechanics studies are being conducted as part of these investigations. This paper describes the design work conducted related to orepasses for a potential new main haulage level. The orepasses are a vital part of the transportation chain and have historically been subject to extensive instabilities leading to closing and the re-development of orepasses in parts of the mine. The objective of the work was two-fold - first to validate rock mass strength and stress state through comparison of modelling results with observed fallouts in orepasses and a ventilation shaft, and second, to determine the optimal orientation and location of orepasses, primarily with respect to stress-induced failures in the orepass walls. The effects of wear were only accounted for implicitly by simulating a change in orepass geometry, through a groove formed in the bottom orepass wall. 
Two orepasses with observed wall damage and orepass enlargement were analysed to validate strengths and stresses: (i) orepass BS216 located near the Alliansen orebody and (ii) orepass BS225 located near the Dennewitz orebody. The developed fallouts and resulting geometrical changes were identified through laser scanning and represented, by a cloud of points and level curves defining the cavity, as shown in Figures 1 and 3. The observed damage led to permanent closure of orepass BS225 and restoration of orepass BS216. Two large-scale geological structures, DZ035 and DZ034, have been inferred in the vicinity of the orepasses (Figure 1). In addition, observed spalling failure in the ventilation shaft E8, near the Dennewitz orebody, was analysed to fine-tune strength calibration. Spalling failure had developed in approximately the first $100 \mathrm{~m}$ of the shaft (the portion accessible for video inspection), as illustrated in Figure 2.

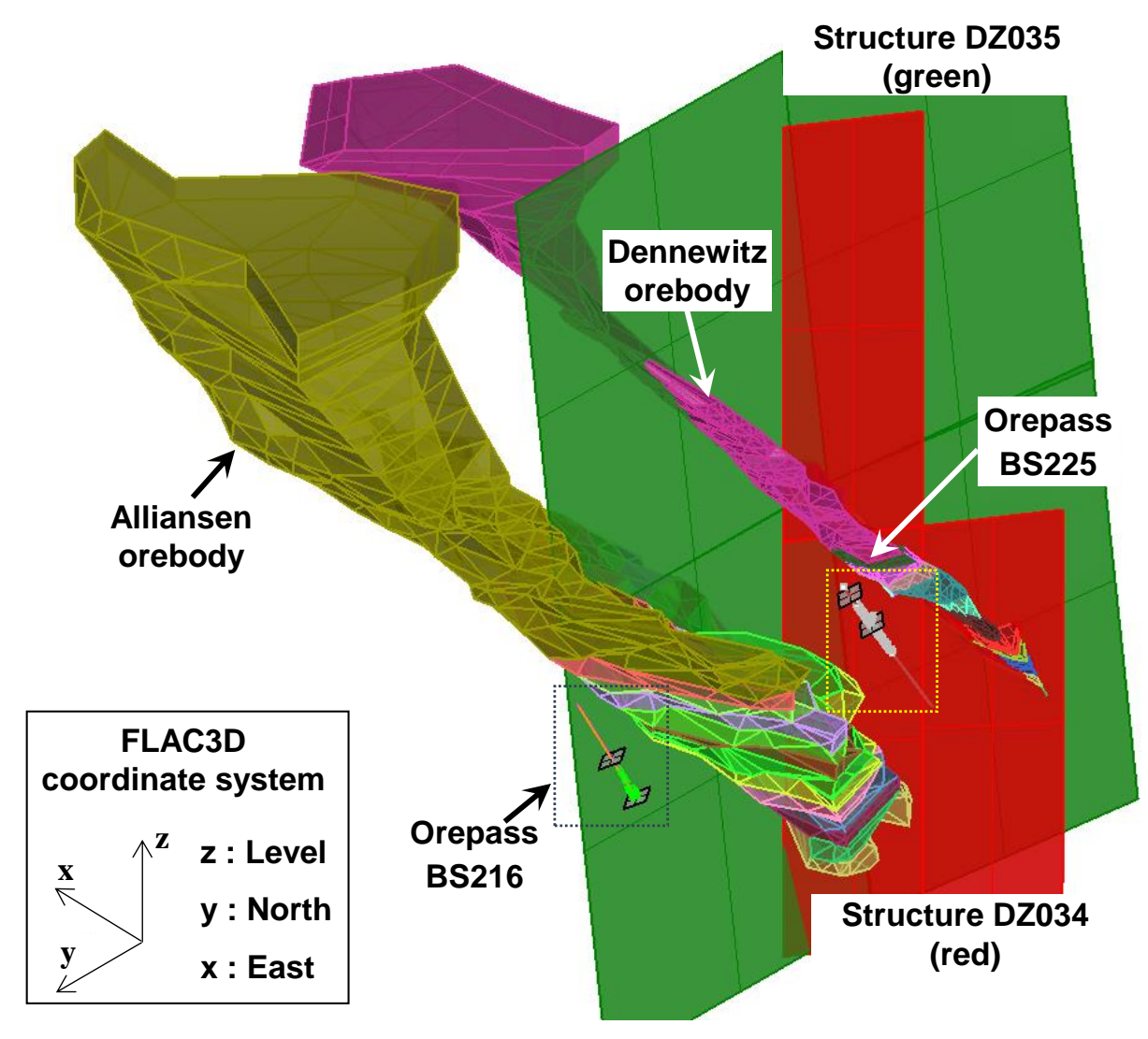

Figure 1 Northwest perspective view of the analysed orepasses
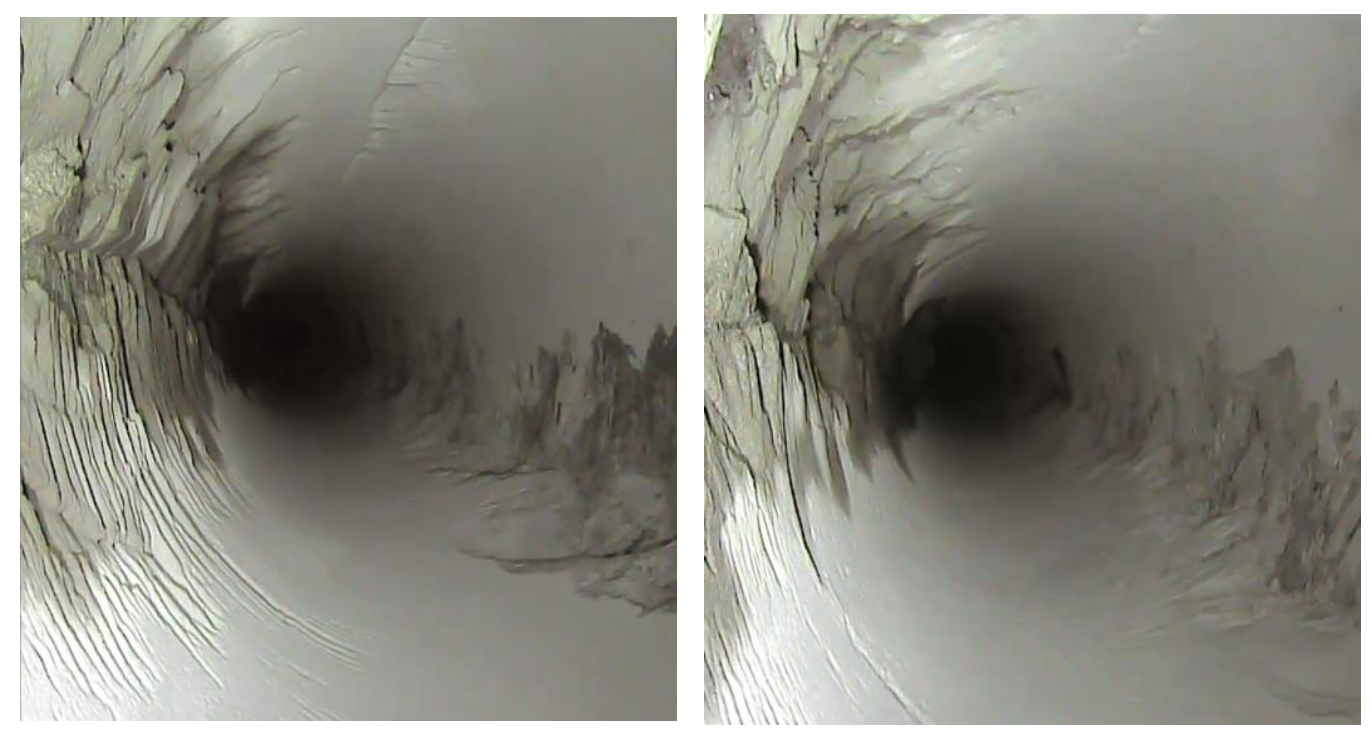

Figure 2 Observed spalling failure in the ventilation shaft E8, at two different levels 
In the final part of the work, the results were applied to the design of orepasses for a new haulage level at depth in the Malmberget mine. Analyses were conducted for two mining areas - the Alliansen-Printzsköld orebody (initially two orebodies that merge into one at depth), and the Fabian orebody, using the calibrated material model and strength parameters from the initial modelling. In this part of the work, different locations and orientations of future orepasses were studied.

\section{$2 \quad$ Methodology and input data}

\subsection{Approach}

A simplified approach was chosen in which a two-dimensional numerical model representing cross-sections perpendicular to the orepass axes were analysed for each of the orepasses. The finite difference code FLAC (Itasca Consulting Group, Inc. 2011) was chosen for the analyses. Boundary stresses to the models were obtained from a three-dimensional mine-scale model, through which the influence of mining in each of the orebodies was quantified (Perman 2013). Stresses from the 3D-model were extracted at the centre points of each analysed cross-section through an orepass. The extracted stress tensors were rotated to the local coordinate system of each FLAC cross-section and the rotated shear and normal stress components were applied to the boundaries of the local model.

Using this approach, it was possible to fairly quickly analyse several cross-sections (levels) of an orepass, as well as different orepass locations, by simply extracting a new set of boundary stresses from the 3D-model and applying them to the local 2D-model. This analysis approach has been utilised previously with good experiences in Sjöberg and Malmgren (2008). For analysis of observed fallouts in the two orepasses near the Alliansen and Dennewitz orebodies, two different cross-sections located at an upper and lower level were modelled. The selected levels were 1148 and $1218 \mathrm{~m}$ for orepass BS216, and 1000 and $1059 \mathrm{~m}$ for orepass BS225. The locations of the analysed cross-sections were chosen based on whether fallout was observed or not. At the upper section of each orepass, there was no observed fallout, but at the lower section, it was noticeable. The sections planes are perpendicular to the orepass axes (Figure 3).

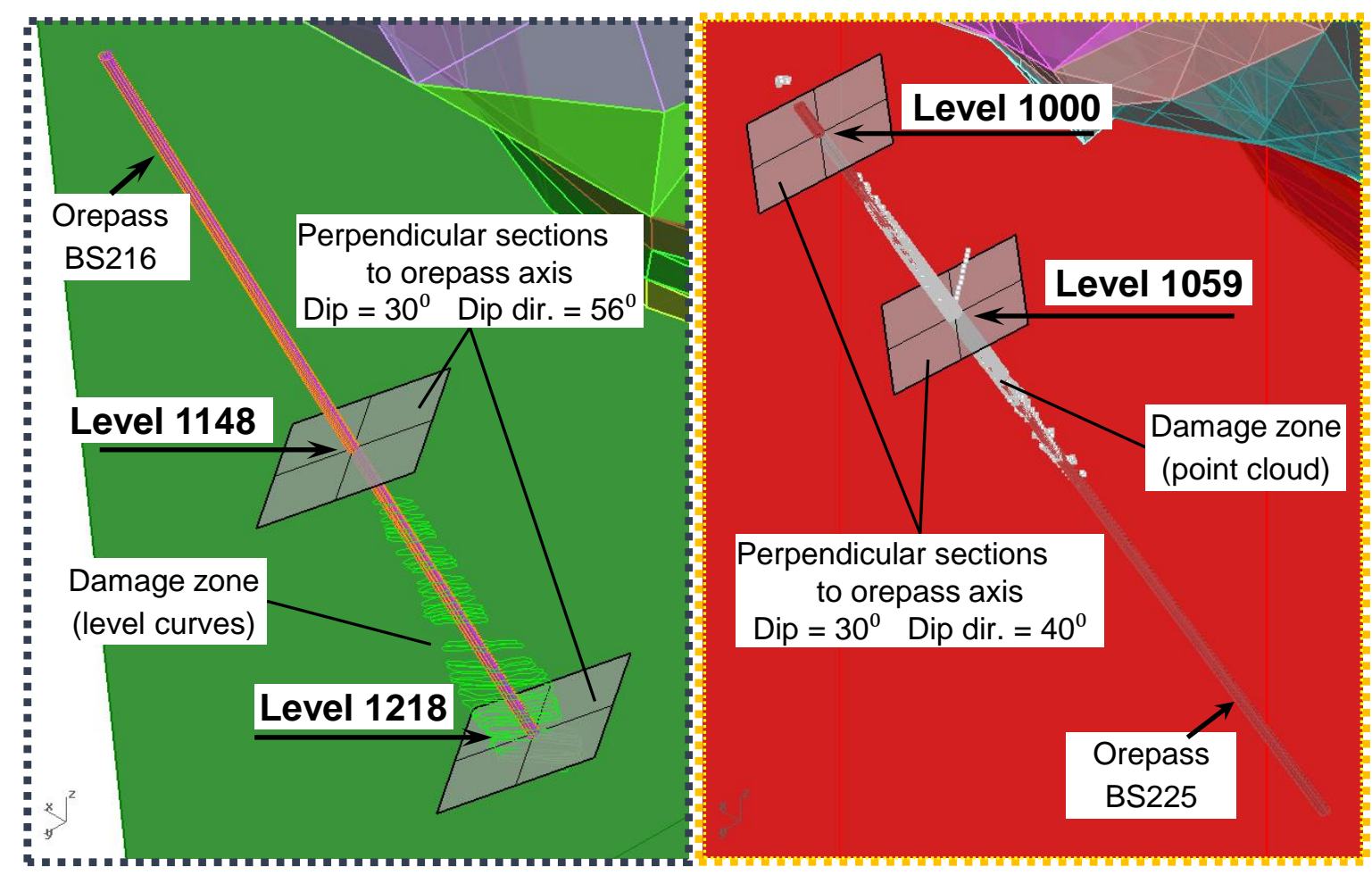

Figure 3 Analysed levels, section plane orientations and observed fallout (close-up view of the two rectangles shown in Figure 1) 
The possible influence from large-scale geological structures in the proximity of the orepasses was analysed by explicitly including a weak zone in the local model. Since the orientation of the orepass and the structures were different, the structure is at different distances from the orepass in different cross-sections. Consequently, several cases were analysed in which the distance from the structure to the orepass was varied.

\subsection{Numerical model setup}

The same type of model was used for all analyses, albeit with small variations. A radial finite-difference mesh was used with the excavated orepass in the centre. The model size was set to $60 \times 60 \mathrm{~m}$ to have at least ten times the orepass diameter (of $3 \mathrm{~m}$ ) from the centre of the model to the external boundary to reduce possible boundary influence. Near the orepass, a $4.5 \mathrm{~m}$ thick 'shell' of elements with higher mesh density was used. All the elements within this area had a length of $10 \mathrm{~cm}$ in the radial direction. An example of the model geometry is shown in Figure 4. For the analysis of the spalling failure in the ventilation shaft an element length of $2.5 \mathrm{~cm}$ was used to be able to replicate the small failure depths.

For the models with large-scale structures included, the model size was increased to $90 \times 90 \mathrm{~m}$. For structure DZ034, three possible location cases were analysed with the structure at 33, 15 and $2 \mathrm{~m}$ from orepass BS225. For structure DZ035, two cases were analysed with the structure at 15 and $2 \mathrm{~m}$ from orepass BS216 (see also Figure 5). These locations were chosen to analyse the scenarios that were deemed to be most critical with respect to the location of the structures. The structures were simulated as a low-strength continuum material of approximately $2.5 \mathrm{~m}$ in width, and with at least two elements across their width.

Stresses from selected mining stages were considered, and extracted from the 3D mine-scale model. For the model calibration, mining stages were chosen covering the period of time in which the orepasses were excavated and the fallouts were observed. In the study of new orepass design, a series of mining stages, from the current situation, and down until mining past the potential new haulage level, were considered. The mining step that produced the highest major principal stress, and the two preceding steps, for each level and at each location, were then selected and used as input to the local model.

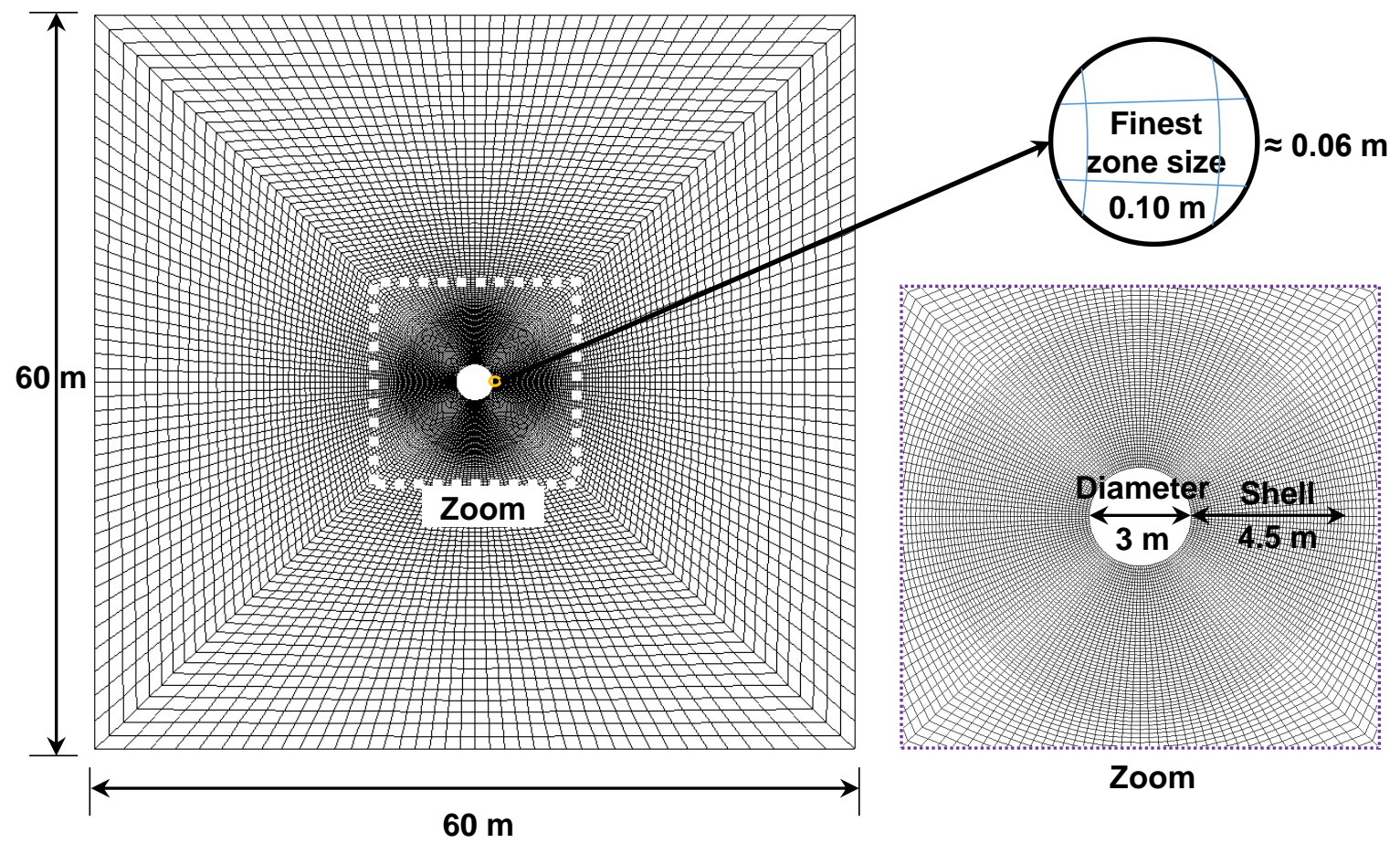

Figure 4 Two-dimensional FLAC model of orepass and close-up of the shell of zones with constant radial length $(0.10 \mathrm{~m})$ 


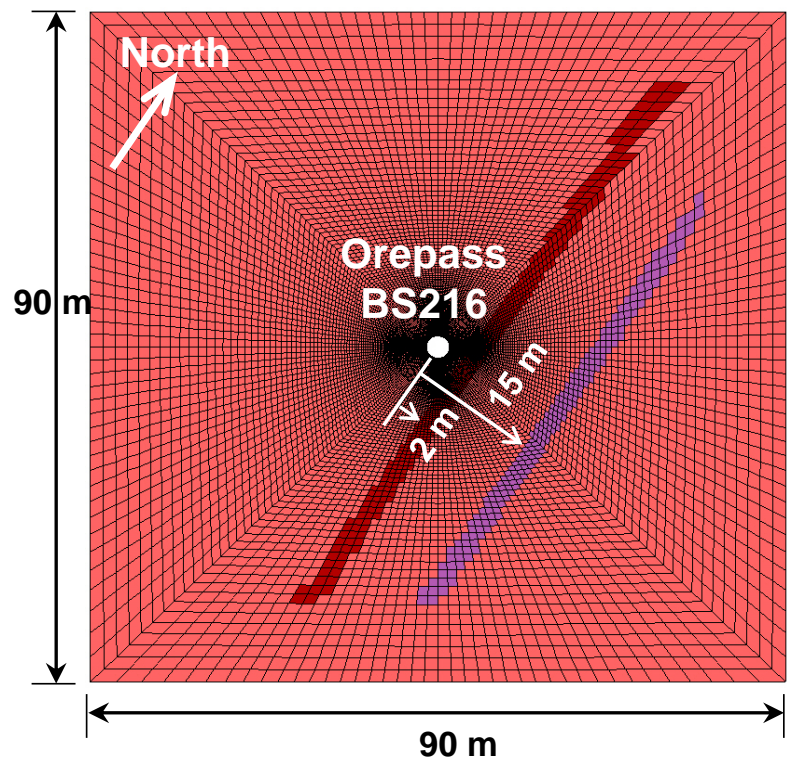

(a)

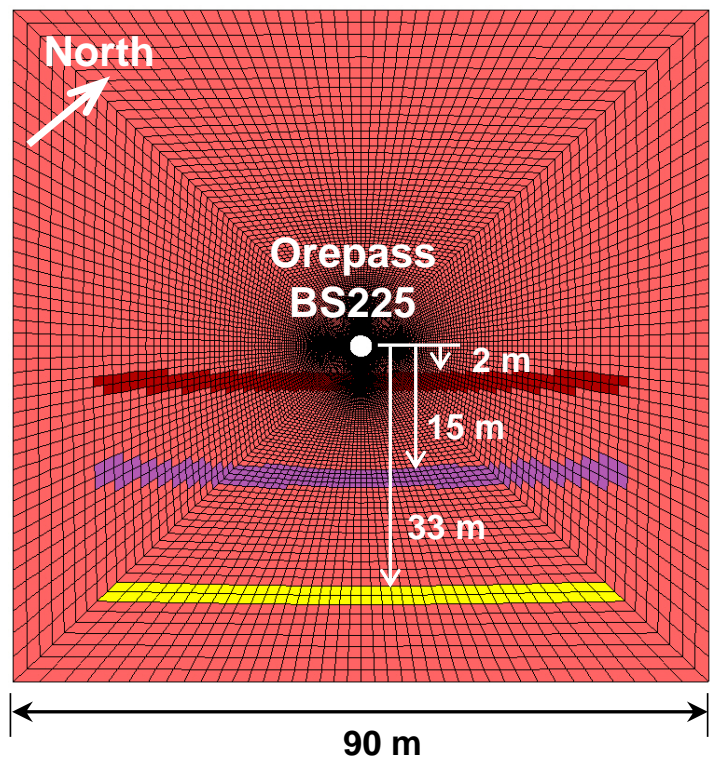

(b)

Figure 5 Analysed cases with deformation zones: (a) orepass BS216 and structure DZ035; and (b) orepass BS225 and structure DZ034

\subsection{Material models and parameter values}

Several constitutive models were used with the purpose of reproducing the observed fallout. This included: (i) linear-elastic perfectly-plastic $\mathrm{M}-\mathrm{C}$ model, (ii) non-linear Hoek-Brown ( $\mathrm{H}-\mathrm{B})$ model, and (iii) non-linear modified H-B (MH-B) model. The H-B model yield function follows the curved Generalised H-B criterion (Hoek et al. 2002) and failure envelope is continuously approximated by the M-C tangent at the current confinement level, whereas the $\mathrm{MH}-\mathrm{B}$ model incorporates a tensile cut-off and uses a linear approximation of the curved $\mathrm{H}-\mathrm{B}$ envelope.

Additionally, a strain softening (SS) model was used to simulate brittle rock mass behaviour by means of the cohesion weakening frictional strengthening (CWFS) approach proposed by Hajiabdolmajid et al. (2002). In this model, the mobilisation of the frictional and cohesional strength components is a function of rock mass damage or plastic strain. The cohesion loss starts from its initial value reaching a constant residual cohesion at the plastic strain limit (eps_Coh). The frictional strength increases from its zero initial value until a constant residual friction is reached at the plastic strain limit (eps_Fric) (Figure 6).

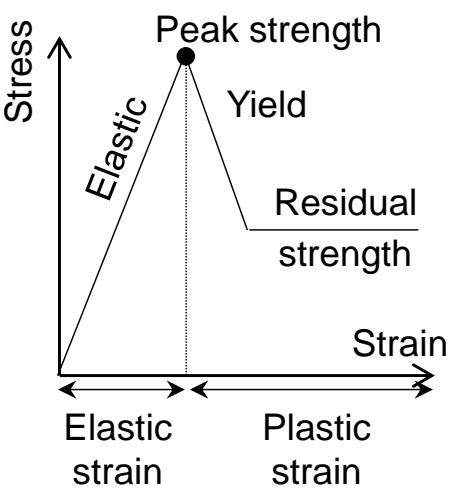

(a)

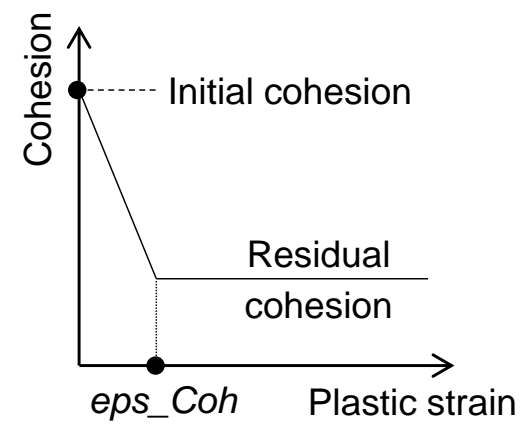

(b)

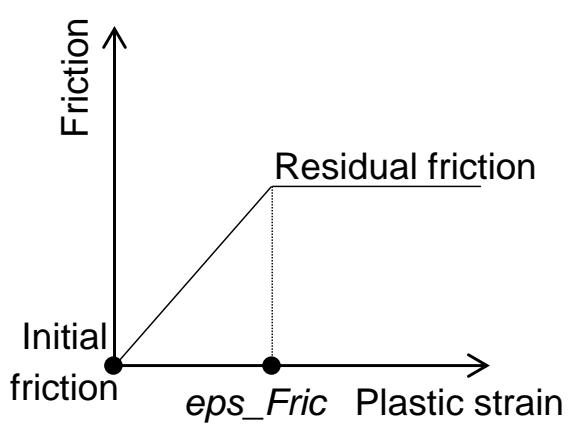

(c)

Figure 6 (a) Strain softening model (SS); and (b) and (c) cohesional and frictional strength mobilisation as function of plastic strain 
These plastic strain limits were found to be primarily dependent on heterogeneity and grain characteristics. Moreover, the eps_Coh was found to be generally lower than the eps_Fric. Therefore, Hajiabdolmajid et al. (2003) introduced a strain-dependent brittleness index $\left(I_{\text {Beps }}\right)$ by the following equation, which considers the delay between the frictional strength mobilisation and the cohesion loss during the failure process:

$$
I_{\text {Beps }}=\left(\text { eps_Fric }-e p s \_C o h\right) / e p s \_C o h
$$

The plastic strain limits were estimated to have a strain-dependent brittleness index value equal or higher than one $\left(I_{\text {Beps }} \geq 1\right)$. These values are in agreement with those used by Hajiabdolmajid et al. (2003) to simulate the brittle failure of Lac du Bonnet granite, in the AECL "Mine-by experiment" (Martin 1997).

The probabilistic estimation of rock mass properties developed by Musa et al. (2013) was used as base input parameters. This data set comprises data from several sources and also considers variations in parameter values. Three material units were selected from Musa et al. (2013) based on the field observations made for the orepasses: red leptite (RL), grey leptite (GL) and biotite I (BI). The resulting mean values for the H-B parameters, as well as for equivalent $\mathrm{M}-\mathrm{C}$ parameters, are shown in Table 1.

For the rock mass strength validation, a sensitivity analysis was conducted in which the rock mass has been simulated as one, homogeneous, rock unit. To simulate representative materials with different strengths, the modelled rock mass unit was assumed to be composed of fractions of the selected material units or of one whole material unit. Therefore, the parameters values were weighted to obtain the input FLAC material properties by the equation:

$$
F L A C \_p=0.01 *\left[R L(\%) * R L \_p+G L(\%) * G L \_p+B I(\%) * B I \_p\right]
$$

where:

$$
\begin{aligned}
F L A C \_p= & \text { calculated weighted parameter assigned to FLAC model. } \\
R L \_p= & \text { red leptite parameter value (analogous for } \left.G L \_p \text { and } B I \_p\right) . \\
R L(\%)= & \text { percentage of red leptite (analogous for } G L(\%) \text { and } B I(\%) \text { ) satisfying the condition: } R L(\%) \\
& +G L(\%)+B I(\%)=100 \% .
\end{aligned}
$$

The strength parameter values used in the SS-CWFS material model are shown in Table 2. The weighted initial cohesion was calculated by the equation $(0.3422 *$ FLAC_UCS), which was obtained assigning the H-B brittle parameters $m_{i}=0$ and $s=0.11$, proposed by Martin et al. (1999) and a perturbation factor $D=0$, to the Hoek et al. (2002) equations. The values for residual cohesion and friction angle were the corresponding values for the perfectly plastic model. The plastic strain limits were estimated based on the work by Hajiabdolmajid et al. (2003), to satisfy the brittleness index values of 1 and 2 . The values from Hajiabdolmajid et al. (2003) apply to hard brittle rock from the Canadian Shield, and were thus judged to be applicable for the present case as well.

The material in the large-scale geological structures can be considered fragmented and with low cohesion, the linear-elastic perfectly-plastic M-C model was judged the most suitable to simulate the deformation zones. The material parameters assigned to the deformation zones were determined using the linear regression approach employed in the RocLab software (Rocscience 2011) (see also Hoek \& Brown 2002). A GSI value of 25 was used to decrease the material strength of the three selected material units, and a stress regression range of $\sigma_{3 \max }^{\prime}=12 \mathrm{MPa}$ was used. The resulting parameter values are shown in Table 3 .

Table 1 Parameter values for H-B and M-C material models

\begin{tabular}{cccccccccc}
\hline Material unit & $\boldsymbol{E}_{\boldsymbol{m}}(\mathrm{GPa})$ & $\boldsymbol{v}_{\boldsymbol{m}}$ & $\mathbf{D}$ & $\boldsymbol{m}_{\boldsymbol{b}}$ & $\boldsymbol{s}$ & $\boldsymbol{a}$ & $\boldsymbol{c}(\mathrm{MPa})$ & $\boldsymbol{\phi}\left(\mathbf{(}^{\circ}\right)$ & $\sigma_{t m}(\mathrm{MPa})$ \\
\hline Red leptite (RL) & 46.7 & 0.22 & 0 & 5.16 & 0.0371 & 0.5014 & 7.89 & 51.17 & 1.60 \\
Grey leptite (GL) & 21.4 & 0.22 & 0 & 2.86 & 0.0213 & 0.5020 & 3.81 & 39.30 & 0.06 \\
Biotite I (BI) & 4.0 & 0.22 & 0 & 1.29 & 0.0130 & 0.5115 & 2.00 & 29.47 & 0.05 \\
\hline
\end{tabular}


Table 2 Strength parameter values, plastic strain limits and brittleness index for SS-CWFS material model

\begin{tabular}{ccccccc}
\hline c_initial (MPa) & c_residual $(\mathrm{MPa})$ & $\phi_{-}$initial $\left(^{\circ}\right)$ & $\phi_{-}$residual $\left(^{\circ}\right)$ & eps_Coh & eps_Fric & $I_{\text {Beps }}$ \\
\hline $0.3422^{*} F L A C \_U C S$ & Weighted $c(\mathrm{M}-\mathrm{C})$ & 0 & Weighted $\phi(\mathrm{M}-\mathrm{C})$ & 0.2 & 0.4 & 1 \\
$0.3422^{*} F L A C \_U C S$ & Weighted $c(\mathrm{M}-\mathrm{C})$ & 0 & Weighted $\phi(\mathrm{M}-\mathrm{C})$ & 0.2 & 0.6 & 2 \\
\hline
\end{tabular}

Table 3 Elastic constants and M-C strength parameters for the large-scale structures (deformation zones)

\begin{tabular}{cccccc}
\hline Deformation zone unit & $E_{m}(\mathrm{GPa})$ & $\boldsymbol{v}_{\boldsymbol{m}}$ & $\boldsymbol{c}(\mathrm{MPa})$ & $\boldsymbol{\phi}\left(^{\circ}\right)$ & $\sigma_{\mathrm{tm}}(\mathrm{MPa})$ \\
\hline Def. red leptite (Def_RL) & 3.8 & 0.22 & 2.83 & 38.2 & 0.05 \\
Def. grey leptite (Def_GL) & 2.0 & 0.22 & 1.80 & 26.8 & 0.03 \\
Def. biotite I (Def_BI) & 1.5 & 0.22 & 1.59 & 24.1 & 0.02 \\
\hline
\end{tabular}

\section{$3 \quad$ Model calibration and validation}

\subsection{Modelling of orepass fallouts}

A parametric study was conducted in which the proportions of rock units were varied and the modelling results compared to the observed fallouts in each of the two orepasses (BS216 and BS225 (Figure 1)). The different constitutive models were tested, and it was found that similar results were found for the $\mathrm{H}-\mathrm{B}$ and MH-B models, compared to the M-C material model. Hence, the sensitivity analysis focused on the M-C material model, together with the strain-softening CWFS material model. Analyses were conducted for both levels in each of the two orepasses (Figure 3). For the CWFS model, the effect of the brittleness index value was also analysed, in addition to the strength parameters and the percentage of each rock unit.

For the $\mathrm{M}-\mathrm{C}$ material model, larger damage zones were found with decreasing rock strength. A fair agreement with observations could be noted; however, the shape of the damage zone was not as elongated as observations indicated (Figure 7). Moreover, the model results indicated larger damage zones in the upper level (due to higher stresses), whereas the field observations showed fallouts only in the lower levels of both orepasses. There are three possible reasons for this: (i) the stress field obtained from the 3D-model does not accurately represent the local in situ stress field, (ii) the in situ rock mass strength is locally higher in the upper levels, and (iii) the influence of transported rock in the orepasses has led to increases in the fallout volume.

By using the brittle CWFS material model, the shape of the damage zone changes to becoming more notch-shaped (Figure 8). The shape and extent of the damage zone was found to fairly replicate the observed fallouts, as shown in Figure 9. Moreover, the effect of changing the brittleness index was small to moderate, with only a slight increase in depth of failure with an increase in brittleness index.

For the deformation zones, the strength parameter values from Table 3 were used as a starting point, but these resulted in very little yielding in the structures, and thus little influence on the nearby orepass. The strength values were then decreased until the structure zones developed considerable plastic yielding (for each of the simulated rock units). The surrounding rock mass was considered to be composed of only grey leptite $(100 \% \mathrm{GL})$ to simulate a lower strength material, which would be more sensitive to the influence of the deformation zone. Since a good agreement was found between the fallout damage shape observed in the field and the results obtained with the CWFS model, the rock mass was simulated with this material model. The results showed that the orepass behaviour was clearly affected by the deformation zone when it was located very close $(2 \mathrm{~m})$ to the orepass boundary (Figure 10). With the deformation zone located at 
larger distances (approximately $10 \mathrm{~m}$ or more) from the orepass boundary, no influence on yielding and/or shear banding could be noticed.

(a)

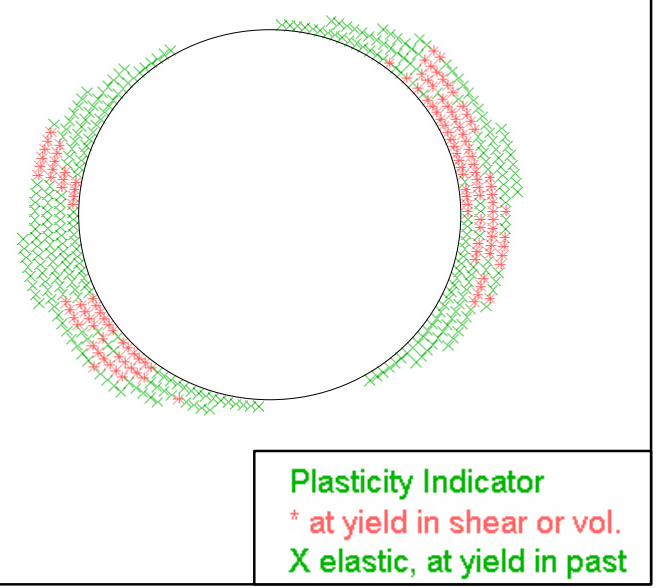

(b)

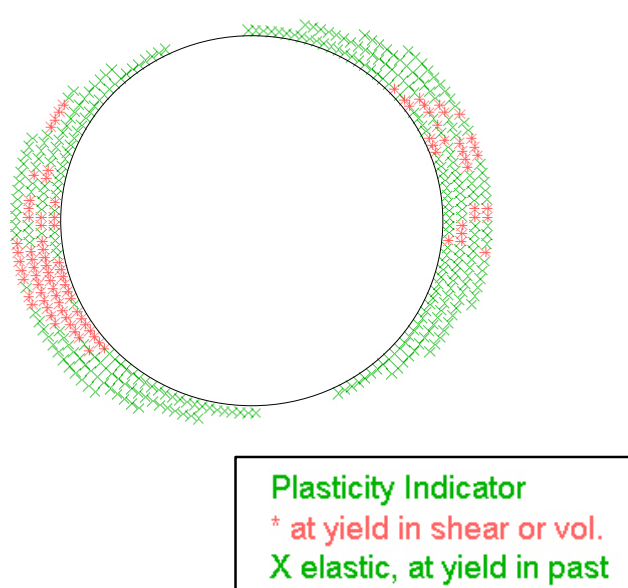

Figure 7 Yielding around orepass BS216 from analysis using FLAC and a perfectly plastic material model with a rock mass composed of $50 \%$ red leptite and $50 \%$ grey leptite: (a) Level 1148 ; and (b) Level 1218

(a)

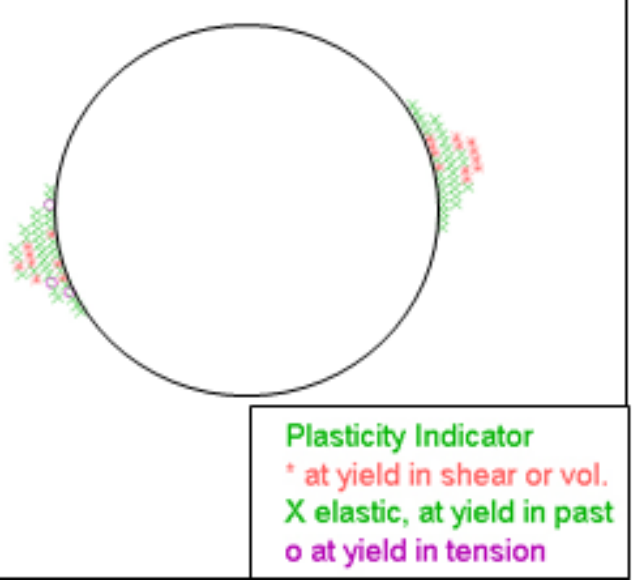

(b)

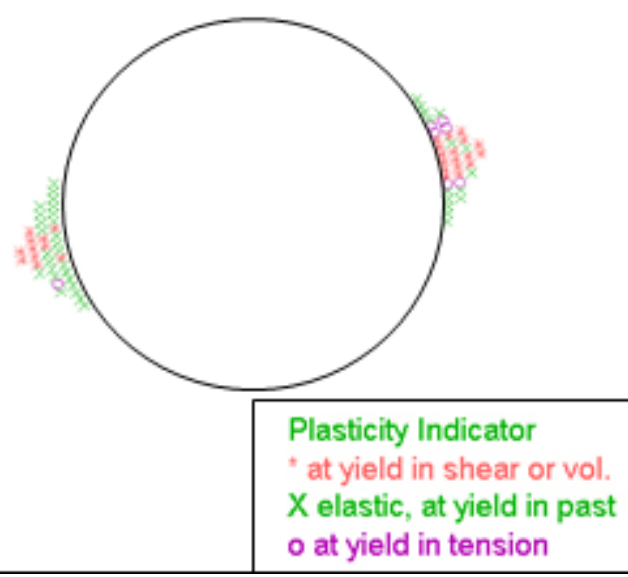

Figure 8 Yielding around orepass BS216 from analysis using FLAC and a brittle CWFS material model with a rock mass composed of 50\% red leptite and 50\% grey leptite: (a) Level 1148; and (b) Level 1218 
(a)

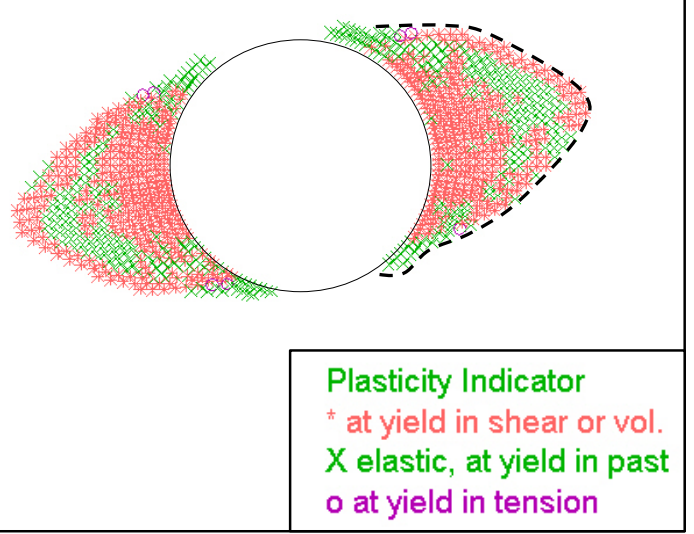

(b)

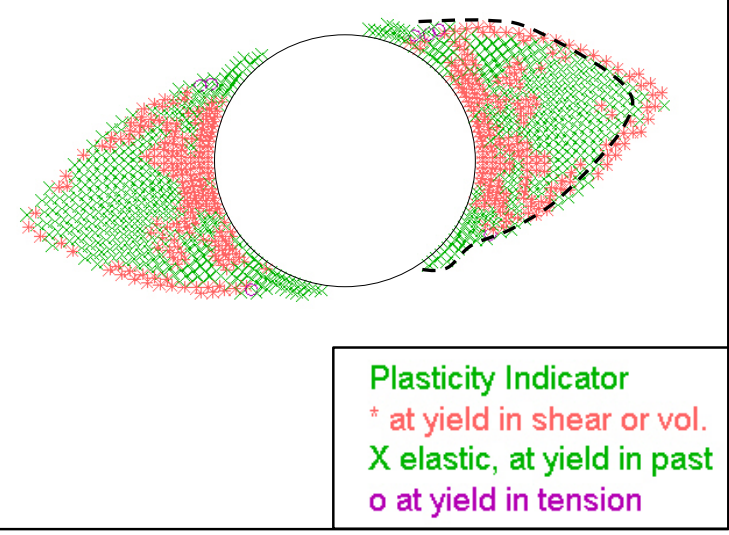

Figure 9 Yielding around orepass BS216 from analysis using FLAC and a brittle CWFS material model with a rock mass composed of $100 \%$ grey leptite at Level $1218 \mathrm{~m}$ : (a) $I_{B E P S}=1$; and (b) $I_{B E P S}=2$. Dashed lines show observed fallouts

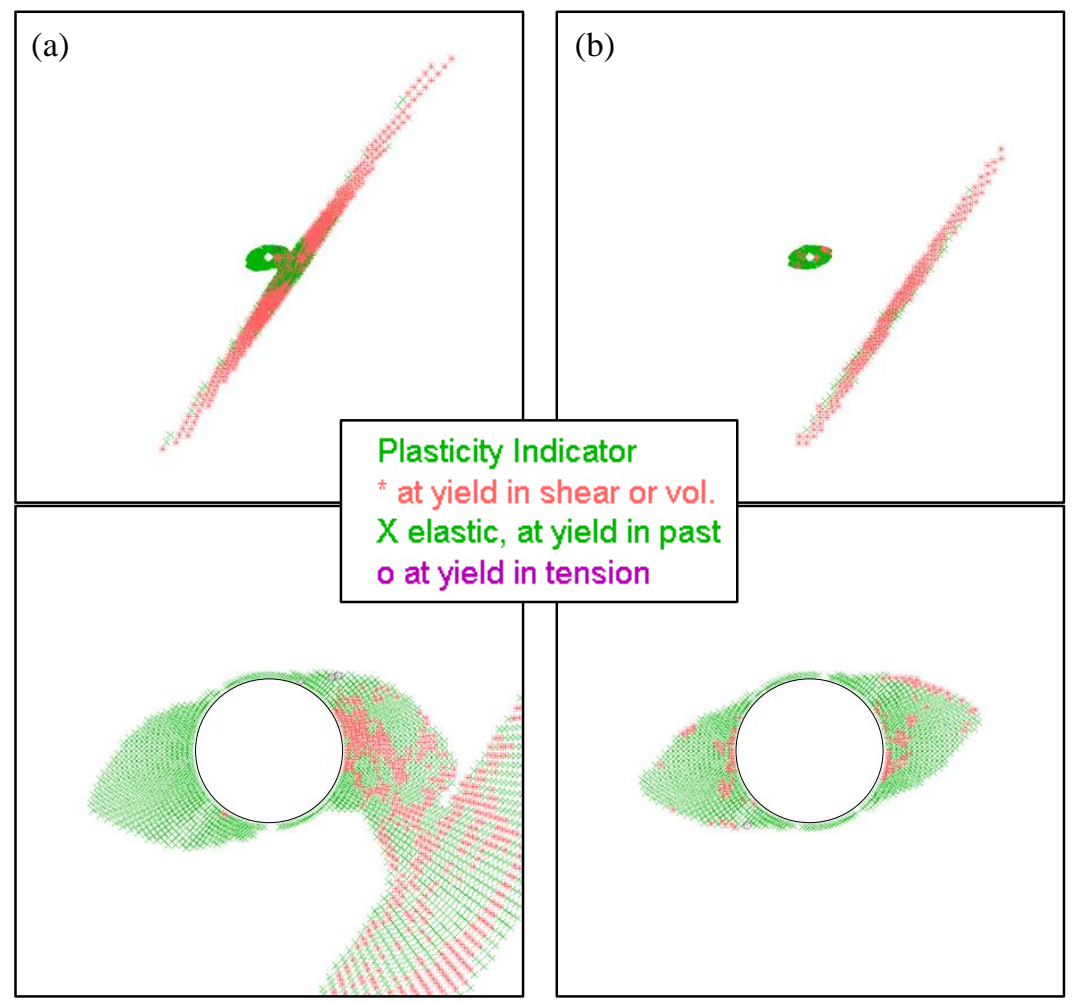

Figure 10 Yielding around orepass BS216 at Level $1148 \mathrm{~m}$ from analysis using FLAC as a function of a nearby large-scale geological structure (deformation zone) at varying distances from the orepass boundary: (a) $2 \mathrm{~m}$; and (b) $15 \mathrm{~m}$. A close-up view is shown in the bottom row of figures

\subsection{Modelling of initial spalling failure in ventilation shaft}

The same approach as outlined above was used for analyses of the observed spalling failures (Figure 2) in the ventilation shaft $\mathrm{E} 8$. The rock mass was simulated as one homogeneous rock unit. Large-scale geological structures were not included as they were located at some distance from the shaft. The CWFS material model was used, but only one level was analysed since the observed damage was found to be similar along 
the $100 \mathrm{~m}$ long inspected portion of the shaft. Four cases were analysed to calibrate the rock mass strength, as shown in Table 4. The brittleness index value was assumed to be 1 with the same plastic strain limits as shown in Table 2.

Table 4 Material properties for analysis of spalling failure in ventilation shaft

\begin{tabular}{lccccccc}
\hline Cases & $E_{m}(\mathrm{GPa})$ & $\boldsymbol{V}_{\boldsymbol{m}}$ & $\begin{array}{c}\boldsymbol{c}_{-} \text {initial } \\
(\mathrm{MPa})\end{array}$ & $\begin{array}{c}\boldsymbol{c}_{-} \text {residual } \\
(\mathrm{MPa})\end{array}$ & $\begin{array}{c}\phi_{-} \text {initial } \\
\left(\mathbf{(}^{\circ}\right)\end{array}$ & $\begin{array}{c}\phi_{-} \text {residual } \\
\left({ }^{\circ}\right)\end{array}$ & $\begin{array}{c}\sigma_{t m} \\
(\mathrm{MPa})\end{array}$ \\
\hline Case 1 & 34 & 0.22 & 50.8 & 5.9 & 0 & 45.2 & 0.83 \\
Case 2 & 37 & 0.22 & 55.5 & 6.3 & 0 & 46.4 & 0.98 \\
Case 3 & 39 & 0.22 & 60.2 & 6.7 & 0 & 47.6 & 1.14 \\
Case 4 & 35 & 0.22 & 53.2 & 6.1 & 0 & 45.8 & 0.91 \\
\hline
\end{tabular}

The results showed that a notch-shaped failure zone developed in the orepass wall, and at the same location as where spalling failure had been observed. Case numbers 1 and 2 resulted in a failure depth of $20-30 \mathrm{~cm}$, i.e. a slight over-estimation of the extent of damage. Case 3 did not cause any yielding (as expected). For Case 4, the depth of failure is $10-12.5 \mathrm{~cm}$, thus being in good agreement with field observations indicating a spalling depth of around $10 \mathrm{~cm}$ (Figure 11). Combining these results, the calibrated rock mass strength for a brittle CWFS material model is according to Table 5.

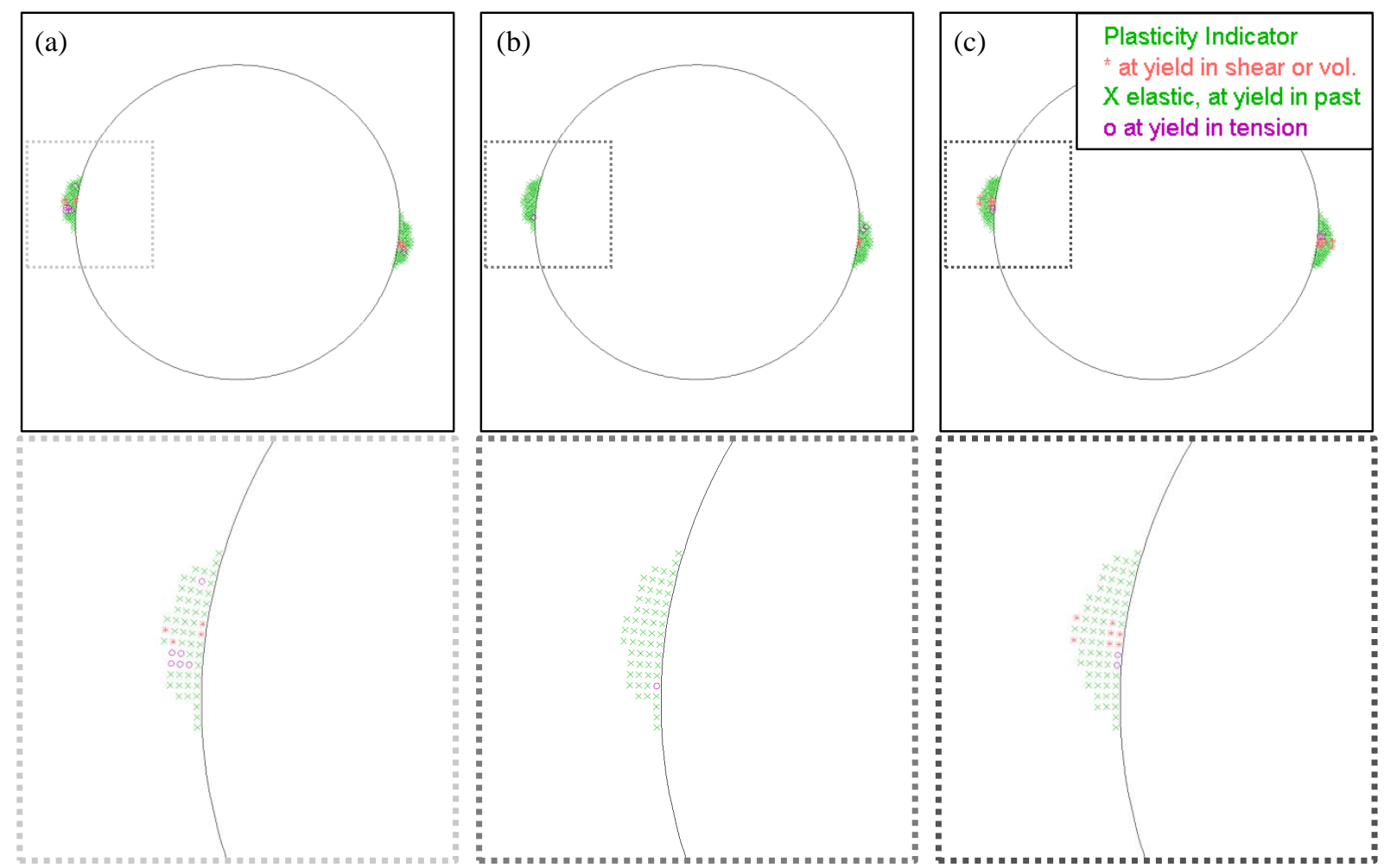

Figure 11 Yielding around ventilation shaft E8 from analysis using FLAC and for Case 4 in Table 4, shown for three mine excavation stages. A close-up view is shown in the bottom row of figures

Table 5 Calibrated rock mass strength parameters for the ventilation shaft E8 using the CWFS material model

\begin{tabular}{cccccccc}
\hline $\begin{array}{c}\text { c_initial } \\
(\mathrm{MPa})\end{array}$ & $\begin{array}{c}\boldsymbol{c}_{-} \text {residual } \\
(\mathrm{MPa})\end{array}$ & $\begin{array}{c}\phi_{-} \text {initial } \\
\left({ }^{\circ}\right)\end{array}$ & $\begin{array}{c}\phi_{-} \text {residual } \\
\left({ }^{\circ}\right)\end{array}$ & eps_Coh & eps_Fric & $I_{\text {Beps }}$ & $\begin{array}{c}\sigma_{\text {tm }} \\
(\mathrm{MPa})\end{array}$ \\
\hline 55.0 & 6.2 & 0 & 46.2 & 0.2 & 0.4 & 1 & 0.95 \\
\hline
\end{tabular}




\section{$4 \quad$ Design considerations for new orepasses}

\subsection{Analysed cases}

As input to the design of orepasses for a potential haulage level at depth in the Malmberget mine, different locations and different orientations of orepasses were analysed. The work focused on the orepasses planned for the Alliansen-Printzsköld orebody, with two different locations and orientations studied, as shown in Figure 12. The first orientation has a dip direction parallel to, while the second has a dip direction perpendicular to, the dip direction of the orebody. A few additional cases were also studied to further analyse the influence of the orepass orientation on the stability conditions. The orepasses in the latter cases were oriented either parallel, or perpendicular, to the trend direction of the major principal virgin stress, i.e. the undisturbed stress prior to mining. In addition, one orepass location close to another orebody (the Fabian orebody) was analysed.

The analysed orepasses dip at $60^{\circ}$ toward south and east respectively, and extend from the 1250 to the $1600 \mathrm{~m}$ Level. They are located at least $75 \mathrm{~m}$ from the footwall boundary. For the Alliansen-Printzsköld orebody, this minimum distance was used at the $1250 \mathrm{~m}$ Level, i.e. at the top of the orepass.

A FLAC-model was setup for a cross-section perpendicular to the orepass axis. Two cross-sections were analysed for an upper and lower level, 1350 and $1500 \mathrm{~m}$ respectively, for each of the orientation alternatives. These levels were chosen arbitrarily but are thought to represent conditions in the upper and lower portion of the long orepasses, but not too close to the old $(1250 \mathrm{~m})$ haulage level. The base model geometry was the same as that described above for the calibration analysis. Wear on the orepass walls was not simulated explicitly; rather, the geometrical effect of extensive wear was modelled by simulating a change in orepass geometry. In this case, a groove formed by wear was simulated in the bottom orepass wall. Also, a de-stressing slot located $3 \mathrm{~m}$ from the orepass boundary and north of the orepass was simulated in selected models (Figure 13). The de-stressing slot was set to $6 \mathrm{~m}$ in length, and $0.5 \mathrm{~m}$ in width, and modelled as a void. In reality, the slot would likely be composed of heavily broken rock from de-stress blasting, but with a low stiffness and thus little ability to carry stress (similar to a void).

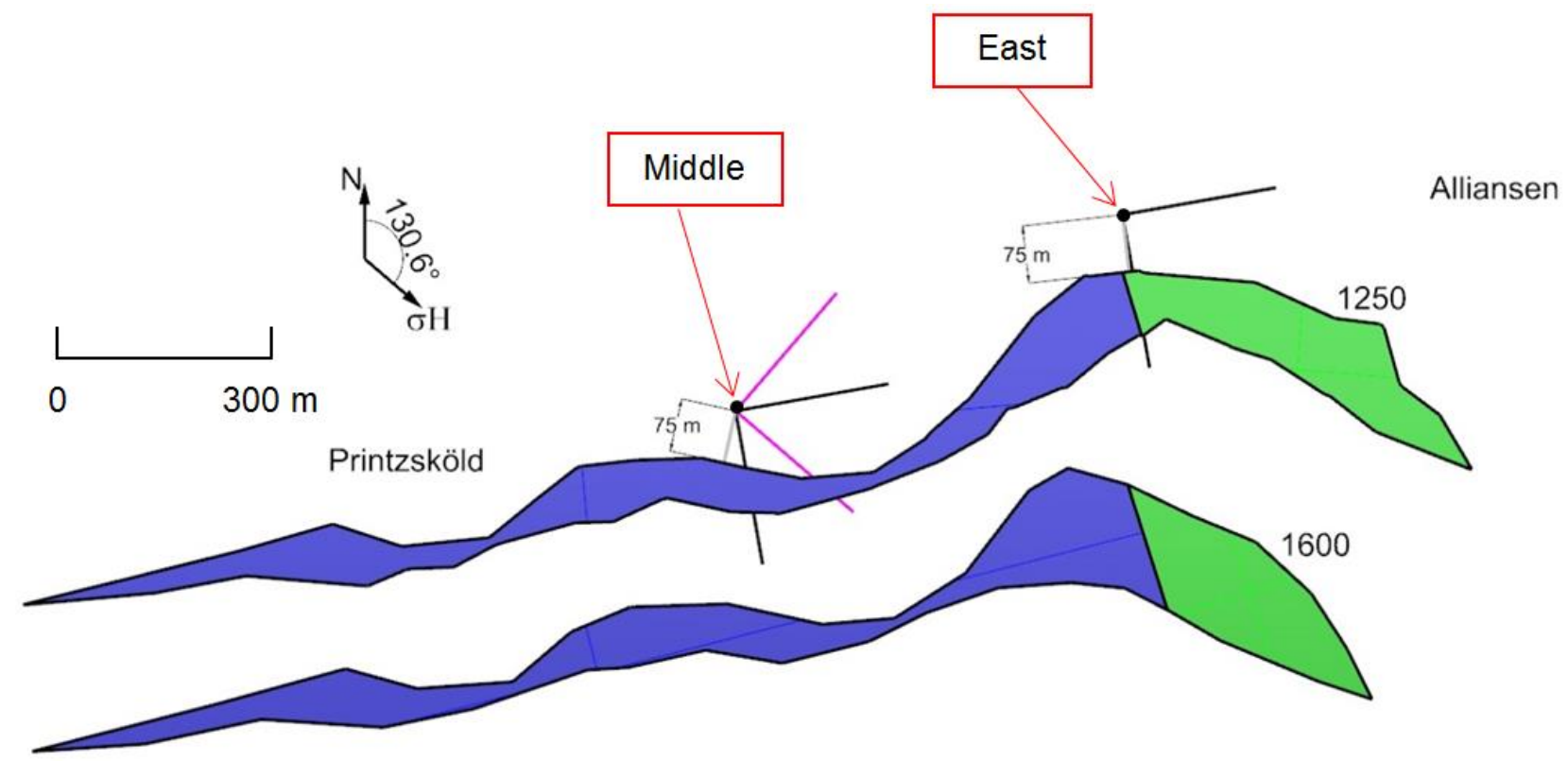

Figure 12 Location of orepass alternatives for the Alliansen-Printzsköld orebody, shown together with orebody plans of Levels 1250 and $1600 \mathrm{~m}$, respectively. Orientations with respect to orebody dip direction displayed in black, and orientations with respect to the trend of the major principal virgin stress $\left(\sigma_{1}=\sigma_{H}\right)$ shown in grey 


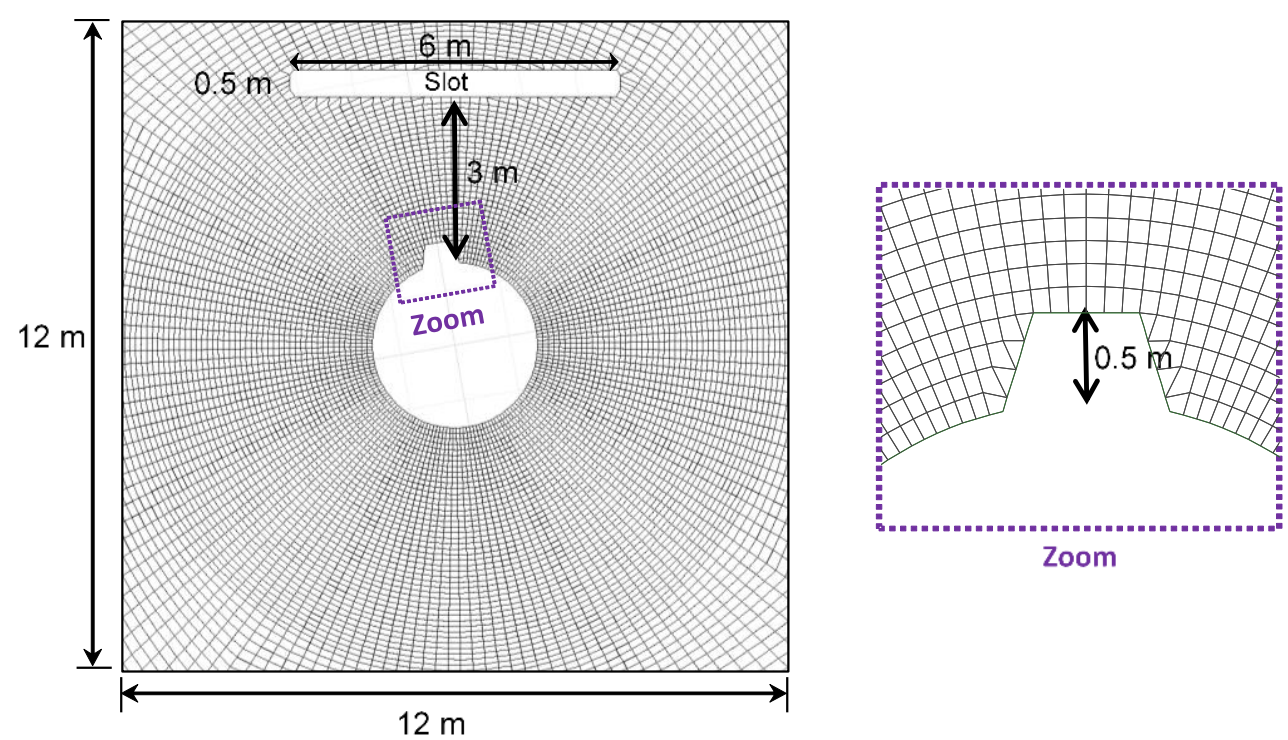

Figure 13 Modified two-dimensional FLAC model of orepass with groove and de-stressing slot

Stress-induced failure was simulated using the brittle CWFS material model, with parameter values determined in the calibration described earlier. Furthermore, progressive spalling was simulated by removing areas of rock that were encompassed by contiguous shear bands. A total of 54 cases (different orientation, location, strength, and geometry) were analysed.

\section{$4.2 \quad$ Results}

The mine-scale stress field was extracted for the three-dimensional numerical linear-elastic model of the Malmberget mine (Perman 2013). An example of the resulting mining-induced stresses (in this case the differential stress) along a line located at $75 \mathrm{~m}$ distance from the orebody boundary at the footwall side, and oriented parallel to the orebody, is shown in Figure 14. The differential stress increases until mining is below the studied level (in this case the $1350 \mathrm{~m}$ Level, and mining steps 22 through 24 in the mine-scale model), after which a distinct stress decrease can be noted. Similar stress charts were developed for other levels as well as for the Fabian orebody, also including charts of the major principal stress direction. These charts can be used as a tool for initial design choices regarding location and orientation of orepasses.

Interpretation of the analysed cases with respect to varying location and orientation of the orepasses showed that the geographical location had the largest influence on the inferred stability of the orepasses. An example is shown in Figure 15. A change in orepass orientation resulted in comparatively small differences in yielding, but with the parallel orientation being slightly more favourable. With increasing depth, more extensive damage was noted in the analysed cross-sections (different levels), but this is over-shadowed by the influences from changes in material strength. A significant increase in damage and shear straining of the rock mass was found as the material strength was reduced (Figure 15).

Analysis of the effect of using a de-stressing slot showed that more extensive yielding developed when a de-stressing slot is introduced, in addition to more pronounced shear banding in the rock mass. This counterintuitive result may be explained by a loss of confinement in the rock mass between the orepass and the de-stressing slot. Thus, the slot does not de-stress the area as much as it redistributes the stresses, creating higher concentrations of stress in some areas and lower in others. In the end, the deconfinement on the rock from the slot will increase yielding and result in higher shear strain.

The simulation of progressive failure, although somewhat subjective in determining what portions to remove from the model, showed that shear banding and yielding continued to progress, with successive removal of damaged rock segments. In this study, the simulation was terminated after six stages of successive removal. It cannot be concluded that a completely stable shape will ever be reached even if the amount of yielded rock is progressively reduced by the notches created. 


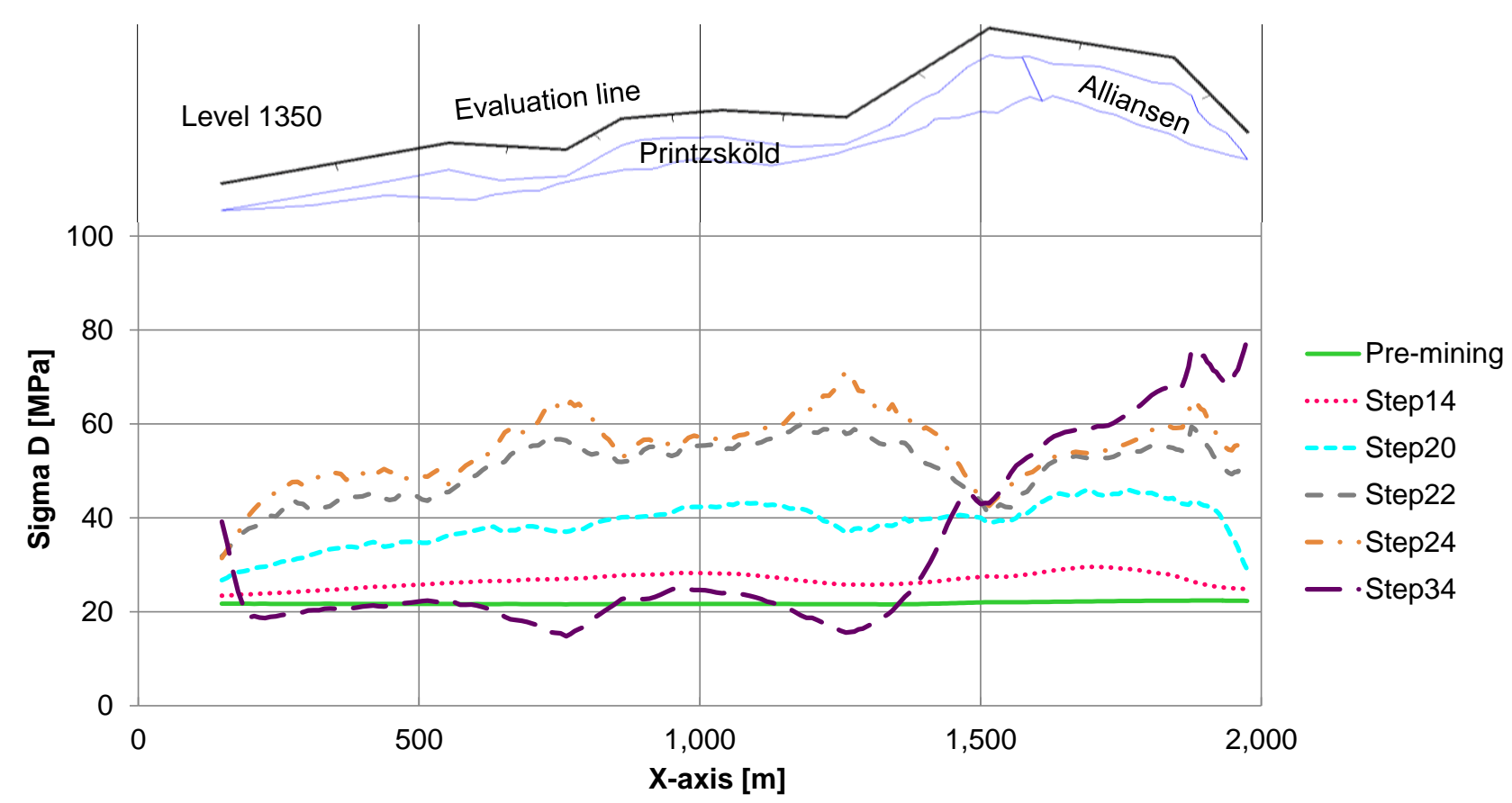

Figure 14 Differential stress along the evaluation line in the footwall of the Alliansen-Printzsköld orebody at the $1350 \mathrm{~m}$ Level

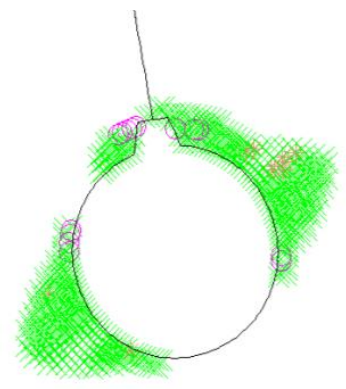

(a)

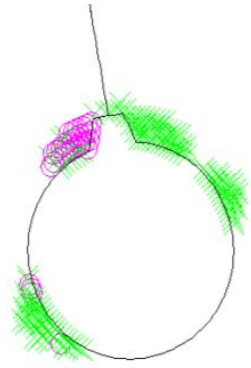

(b)

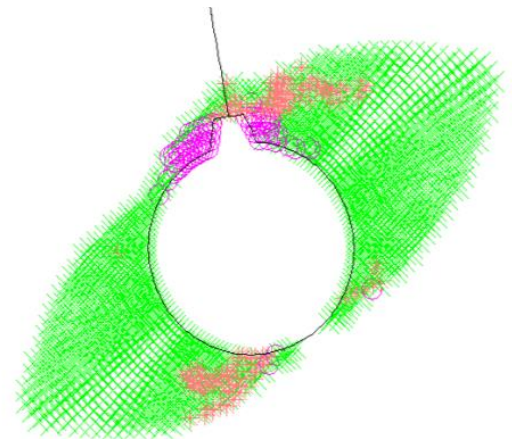

(c)

Figure 15 Yielding around orepass from analysis using FLAC for an orientation parallel to the orebody dip direction: (a) middle location; (b) east location (Figure 12); and (c) east location and lower strength

\section{$5 \quad$ Conclusion and design recommendations}

Observed fallouts and spalling failure in orepasses and ventilation shafts have been analysed, and the following conclusions could be drawn:

- The notch-shaped fallouts in the orepasses as well as the spalling failure in the ventilation shaft were only successfully reproduced by using a brittle CWFS material model. The rock mass strength was successfully calibrated through comparison with observations.

- The results further showed that the presence of a deformation zone (large-scale geological structure) significantly influenced the orepass stability, when the zone was in close proximity to the orepass boundary. However, when the deformation zone was farther away (approximately $10 \mathrm{~m}$ or more), no effects on the orepass was seen.

- The extent of the simulated damage zone was slightly larger in the upper levels of the orepasses, in contrast to field observations. Damage caused by orepass usage is most likely the main cause 
for the discrepancies between simulations and field observations, but local variations in rock mass strength may also explain these differences.

For the design of new orepasses, the following conclusions and recommendations apply:

- The differences between different analysed orientations of the orepasses are small, but overall an orientation parallel to the orebody dip direction is preferable from a stability perspective.

- For the Alliansen-Printzsköld orebody, an orepass location in the east portion of the orebody is more advantageous. This is primarily due to stresses generally being lower for the east location. The choice of location is significant for the orepass stability and other locations might be even more advantageous, but that needs further evaluation. Moreover, if the rock mass is known to be much poorer in the east location, this conclusion will need to be revised.

- The difference between the studied levels (depths) is smaller than that between most of the other case variables and will only be a problem in combination with poor rock mass and less preferable location.

- At this stage, a de-stressing slot cannot be recommended, as deconfinement of the rock mass leads to an increase in rock mass damage near the orepass.

- Progressive geometrical changes due to wear (from transported rock) were not simulated in this study. Extensive wear may be expected, which may lead to larger cross-sectional area in the orepasses, which, in turn, may lead to stress-induced spalling failure at other locations and to a larger extent than indicated in this study. Additional work may be required to address this issue.

- A three-dimensional stress model of the orepass should be considered. A 2D-model, such as the one used in this study, requires assumptions that may not be completely fulfilled for all analysed mining stages. Initially, a linear-elastic three-dimensional analysis may be performed to compare and possibly verify the corresponding two-dimensional analysis.

\section{Acknowledgement}

The work presented in this paper was funded by LKAB. The approval to publish and present the work is greatly appreciated. Thanks are also extended to Jimmy Töyrä at LKAB for expeditious review of the paper.

\section{References}

Hajiabdolmajid, V, Kaiser, PK \& Martin, CD 2002, 'Modelling brittle failure of rock', International Journal of Rock Mechanics and Mining Sciences, vol. 18, no. 4, pp. 731-741.

Hajiabdolmajid, V, Kaiser, PK \& Martin, CD 2003, 'Mobilised strength components in brittle failure of rock', Geotechnique, vol. 53, no. 3, pp. 327-336.

Hoek, E, Carranza-Torres, C \& Corkum, B 2002, 'Hoek-Brown failure criterion - 2002 edition', Proceedings of the 5th North American Rock Mechanics Symposium and the 17th Tunnelling Association of Canada Conference (NARMS-TAC 2002), Mining and tunneling innovation and opportunity, University of Toronto, Toronto, ON, pp. 267-273.

Itasca Consulting Group, Inc. 2011, FLAC software, version 7.0, Itasca Consulting Group, Inc., Minneapolis, MN, http://www.itascacg.com/software/flac

Martin, CD 1997, 'Seventeenth Canadian Geotechnical Colloquium: The effect of cohesion loss and stress path on brittle rock strength', Canadian Geotechnical Journal, vol. 34, no. 5, pp. 698-725.

Martin, CD, Kaiser, PK \& McCreath, DR 1999, 'Hoek-Brown parameters for predicting the depth of brittle failure around tunnels', Canadian Geotechnical Journal, vol. 36, no. 1, pp. 136-151.

Musa, Al, Basarir, H, Nordlund, E \& Wettainen, T 2013, 'The probabilistic estimation of rock masses properties in Malmberget mine, Sweden', Electronic Journal of Geotechnical Engineering, vol. 18, pp. 269-387.

Perman, F 2013, 3D mine scale modeling of the Malmberget mine for the new main haulage level, report, no. 13-834E, prepared for LKAB, Luleå.

Rocscience 2011, RocLab software, version 1.032, Rocscience, Toronto, ON, https://www.rocscience.com/documents/ pdfs/uploads/8076.pdf.

Sjöberg, J \& Malmgren, L 2008, 'Application of global-local modeling to mining rock mechanics problems', Proceedings of the First International FLAC/DEM Symposium, Itasca Consulting Group, Inc., Minneapolis, MN, pp. 351-358. 